\title{
Germ Cell Intercellular Bridges
}

\author{
Michael P. Greenbaum ${ }^{1}$, Tokuko Iwamori ${ }^{2}$, Gregory M. Buchold ${ }^{2,3}$, and Martin M. Matzuk ${ }^{2,3,4}$ \\ ${ }^{1}$ Department of Radiation Oncology, Baylor College of Medicine, Houston, Texas 77030 \\ ${ }^{2}$ Vanderbilt University Medical Center, Nashville, Tennessee 37232; Departments of Pathology and \\ Immunology, Baylor College of Medicine, Houston, Texas 77030 \\ ${ }^{3}$ Molecular and Cellular Biology, Baylor College of Medicine, Houston, Texas 77030 \\ ${ }^{4}$ Molecular and Human Genetics, Baylor College of Medicine, Houston, Texas 77030 \\ Correspondence: mmatzuk@tmc.bcm.edu
}

Stable intercellular bridges are a conserved feature of gametogenesis in multicellular animals observed more than 100 years ago, but their function was unknown. Many of the components necessary for this structure have been identified through the study of cytokinesis in Drosophila; however, mammalian intercellular bridges have distinct properties from those of insects. Mammalian germ cell intercellular bridges are composed of general cytokinesis components with additional germ cell-specific factors including TEX14. TEX14 is an inactive kinase essential for the maintenance of stable intercellular bridges in gametes of both sexes but whose loss specifically impairs male meiosis. TEX14 acts to impede the terminal steps of abscission by competing for essential component CEP55, blocking its interaction in nongerm cells with ALIX and TSG101. Additionally, TEX14-interacting protein RBM44, whose localization in stabile intercellular bridges is limited to pachytene and secondary spermatocytes, may participate in processes such as RNA transport but is nonessential to the maintenance of intercellular bridge stability.

Intercellular communication is an essential function for all multicellular organisms. Almost every process in the human body, including reproduction, depends on intercellular communication. All of the common methods of intercellular communication found in humans can also be found in the reproductive system. Some examples include endocrine signaling along the hypothalamic-pituitarygonadal axis, paracrine and autocrine signaling from Sertoli cells (Saez et al. 1987), and gap junction communication. Germ cells also use an additional, unique method of intercellular communication in the form of large, $0.5-3-\mu \mathrm{m}$, stable intercellular bridges, sometimes called cytoplasmic bridges. The scale of intercellular bridges makes them unlike any other form of intercellular communication. They join the cytoplasm of neighboring germ cells, forming syncytium, and are large enough to allow the passage of mitochondria, let alone molecular signals. Intercellular bridges are conserved more than a billion years of evolution from insects to humans. They are formed during cell division in both male and female gametogenesis. Although they have been studied in

Editors: Paolo Sassone-Corsi, Margaret T. Fuller, and Robert Braun

Additional Perspectives on Germ Cells available at www.cshperspectives.org

Copyright (C) 2011 Cold Spring Harbor Laboratory Press; all rights reserved; doi: 10.1101/cshperspect.a005850

Cite this article as Cold Spring Harb Perspect Biol 2011;3:a005850 
M.P. Greenbaum et al.

A

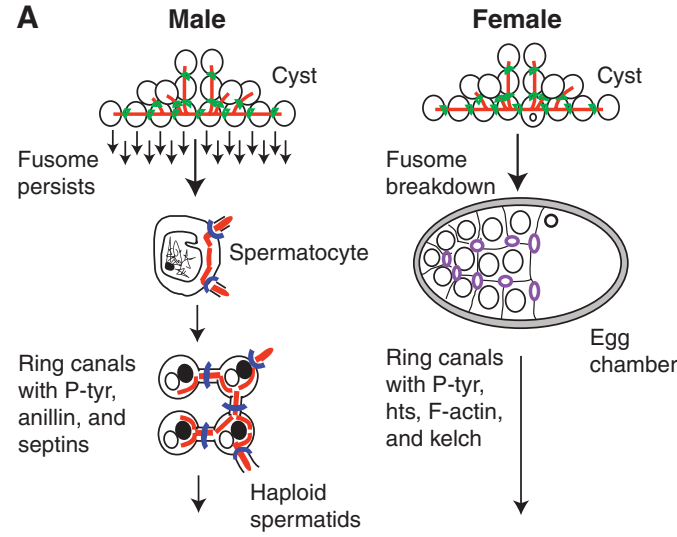

C Male meiotic ring canal formation Early telophase

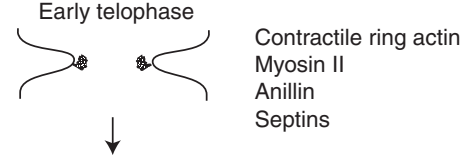

Late telophase, Contractile ring actin
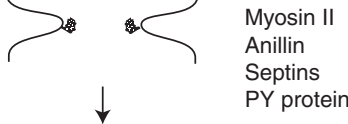

Mature ring canal

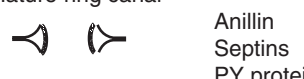

PY protein

$E$

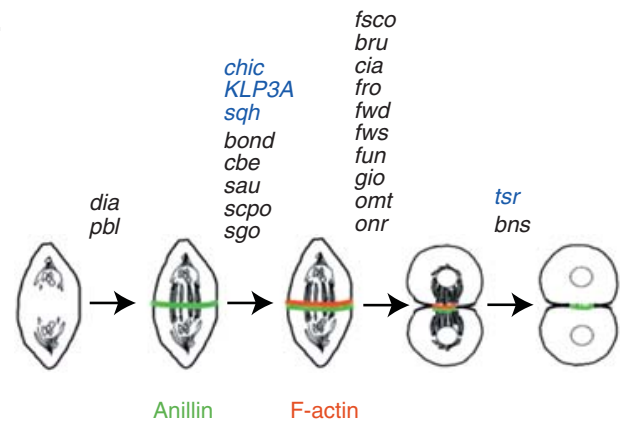

B
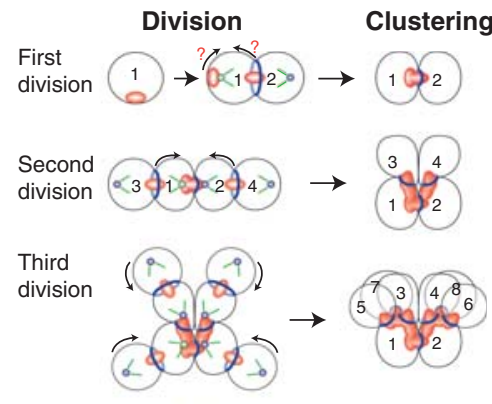

Fourth division (2)

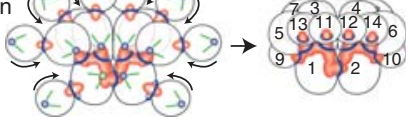

D Ovarian meiotic ring canal formation Arrested cleavage furrow

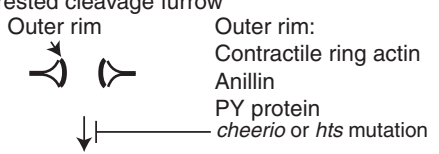

Partly assembled ring canal

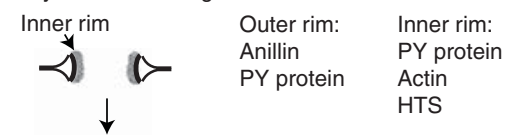

Completely assembled ring canal

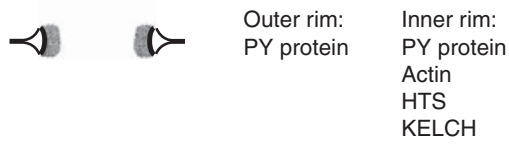

$\mathbf{F}$

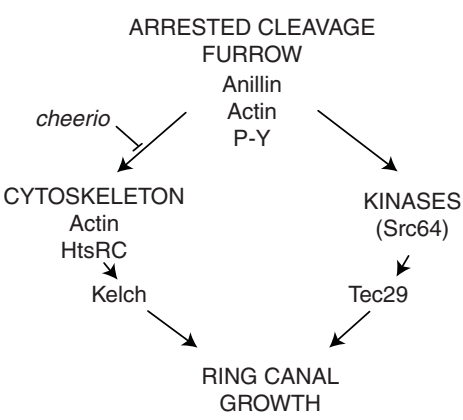

Figure 1. Intercellular bridge formation in Drosophila. Both male and female germ cells initially go through four divisions to form a 16-cell cyst $(A, B)$. In males, meiotic divisions increase the number of germ cells in the cyst to 64. These cells remain connected through the intercellular bridges by the fusome $(A)$. In females, the fusome initially connects all 16 cells through intercellular bridges, with two cells containing the greater fraction of the fusions ( $B$, cells 1 and 2). The fusome then breaks down after oocyte selection. (A, Adapted from Hime et al. 1996; reprinted with permission from The Company of Biologists (C) 1996. B. Adapted from Huynh and St Johnston 2004; reprinted with permission from Elsevier (C) 2004.) Both male (C) and female (D) Drosophila intercellular bridge formation begins in both sexes with an increase in phosphotyrosine epitopes, but subsequent processes are distinct. (See facing page for legend.) 
detail by microscopy for more than half a century, we have only recently begun to learn how mammalian germ cell intercellular bridges form and function at the molecular level. Inroads have been made to determine the role of this unique mode of intercellular communication. Many molecules and organelles have been observed to pass through intercellular bridges, but their role in fertility is not fully understood. Although the bridges themselves have been conserved, the way they form and their function appears to vary between gender and species.

This article will review our current understanding of how intercellular bridges form and the role they play in gametogenesis. Examples will primarily be drawn from mammalian and Drosophila models where the most study has been completed. We will first provide a general description of somatic cell cytokinesis, because modification of this process forms intercellular bridges. Next, we will review Drosophila melanogaster ring canals, the name given to intercellular bridges in that species. We will conclude with what is known about formation and function of mammalian intercellular bridges.

\section{INTERCELLULAR BRIDGES (RING CANALS) IN DROSOPHILA MELANOGASTER}

Syncytial development of germ cell cysts is conserved from fruit flies to mammals in both males (Burgos and Fawcett 1955; Fawcett et al. 1959; Dym and Fawcett 1971; Moens and Hugenholtz 1975; Huckins and Oakberg 1978; Weber and Russell 1987; Ren and Russell 1991; Ventela et al. 2003) and females (Gondos et al.
1971; Pepling and Spradling 1998, 2001; Pepling et al. 1999). Drosophila male and female gametes develop clonally (Rasmussen 1973; Spradling et al. 2001; Gonzalez-Reyes 2003) from a single founder cell, the gonial cell in males and the cystoblast in females. In both genders, the founder cell initially divides four times. "Incomplete" cytokinesis during these divisions results in the formation of a 16-cell cyst (Fig. 1A) (Hime et al. 1996; Huynh and St Johnston 2004). The cells of the cyst are connected by intercellular bridges, also called ring canals in Drosophila. The number of intercellular bridges borne by each germ cell in the cyst directly correlates to the round of division from which it was derived. Thus, the founder cell and its first daughter cell will each have four intercellular bridges, their two daughter cells will have three bridges, the next four cells will have two bridges, and the final eight cells have only one bridge, for a total of 15 shared intercellular bridges (Fig. 1B) (intercellular bridges in cysts are in green).

Sixteen cells is the final number of germ cells in the ovarian cyst. Once this number is reached, the cyst migrates posteriorly in the ovary as it matures, and one germ cell will be selected as the oocyte and supported by the other 15 "nurse" cells (Huynh and St Johnston 2004). When male cysts reach 16 cells, two meiotic divisions occur to form a total of 63 shared intercellular bridges. This pattern of division is highly reproducible and, at least in females, is dependent on a structure called the fusome. By comparison, the number of cells in a mammalian germ cell cyst is much greater and less regulated (see below). Furthermore, no

Figure 1. (Continued) Male cleavage furrows lose actin and myosin but retain anillin and septins (C), whereas female cleavage furrows form an inner ring with Hts and Kelch and lose anillin $(D)$. ( $D$, Adapted from Robinson and Cooley 1996; reprinted with permission from Elsevier (C) 1996.) (E) Genes for specific steps in cytokinesis in Drosophila spermatocytes are shown. The mutants often prevent the formation of intercellular bridges, demonstrating the close relationship between cytokinesis components and intercellular bridge formation in male Drosophila. The gene names, and homologs when known, are provided in the text. (E, Adapted from Giansanti et al. 2004; reprinted with permission from American Society for Cell Biology (C) 2004.) (F) Cytoskeletal and nontyrosine kinase pathways intersect to form female intercellular bridges. Src kinase activates Tec29, which localizes to the forming intercellular bridge. Phosphorylation of cytoskeletal components, such as kelch, is necessary for intercellular bridge formation. It is unknown which kinase is responsible for phosphorylating kelch. ( $F$, Adapted from Cooley 1998; reprinted with permission from Cell Press (C) 1998.) 
M.P. Greenbaum et al.

equivalent of the fusome has been identified in mammals.

The fusome (Fig. 1A,B, red) is a structure containing spectrin and hu-li tai shao (Hts), an adducin homolog (Yue and Spradling 1992) that connects the germ cells of the cyst through their intercellular bridges. The fusome is derived from a spherical structure in the germline stem cell called the spectrosome (Lin et al. 1994; de Cuevas et al. 1996). In females, the cystoblast inherits one third of the fusome from the germline stem cell (Deng and Lin 1997). As the germ cells divide to form the cyst the fusome grows and is distributed, but a larger fraction of the fusome is kept in one of the two cells formed by the first division. This asymmetric division is repeated three times. At the end, the cell with the most fusome material (one of the first two cells) will become the oocyte (de Cuevas and Spradling 1998), and the fusome breaks down (Fig. 1B). Hts and $\alpha$-spectrin mutants lack a fusome and fail to specify an oocyte. Additionally, the divisions become randomly oriented and result in a variable number of cells (Yue and Spradling 1992; Lin et al. 1994; de Cuevas et al. 1996). In males, all 16 germ cells of the cyst are equivalent, and the fusome is maintained although meiosis and connects all 64 haploid spermatids (Fig. 1B) (Hime et al. 1996). The fusome plays a role in centrosome inheritance in spermatogenesis. A male sterile allele of $h t s$ eliminates the fusome. In this mutant dividing spermatogonia all have two centrosomes and a normal mitotic spindle, but spermatocytes have a variable number of centrosomes and defective spindles.

Passage of the fusome through intercellular bridges is a common feature of male and female Drosophila gametogenesis, and fusome communication through intercellular bridges is essential for fertility. Although intercellular bridges play a similar role in both genders in this respect, the mechanism of intercellular bridge formation differs in male and female Drosophila.

Stable intercellular bridges between male germ cells are composed of proteins involved in cytokinesis (Hime et al. 1996), namely, anillin and three Drosophila septins, Peanut (Pnut), Sep1, and Sep2. Septins are required for somatic cell cytokinesis in some, but not all, cell types (Glotzer 2005), and are capable of self-assembly into rings (Kinoshita et al. 2002). Anillin, which localizes early to the cleavage furrow (Field and Alberts 1995), directly interacts with septins (Field and Alberts 1995; Kinoshita et al. 2002), and was initially identified as an actin-binding protein in Drosophila embryos (Miller et al. 1989).

The earliest sign of intercellular bridge formation in both male and female Drosophila is the appearance of phosphotyrosine epitopes in late telophase (Fig. 1C,D) (Robinson and Cooley 1996). These "rings" of phosphotyrosine epitopes remain in the intercellular bridge even after it matures, growing in diameter with the bridge as the germ cells develop. After the appearance of phosphotyrosine epitopes, myosin II and actin from the contractile ring are lost from the mature intercellular bridge in male Drosophila (Fig. 1C). In contrast, actin remains a major component of the mature female intercellular bridge (Fig. 1D), but anillin and septins are no longer present. These are not the only compositional differences between male and female Drosophila intercellular bridges. Hts and kelch, essential proteins in the female intercellular bridge, are absent from male bridges. In fact, only one protein has been identified as a component of both male and female intercellular bridges, Pavarotti/MKLP1 (Carmena et al. 1998; Minestrini et al. 2002). Interestingly, although male germ cell intercellular bridges have different components from female germ cell intercellular bridges, they may be similar to intercellular bridges that have been reported connecting somatic cells of the follicular epithelium in ovary, imaginal disc cells, and larval brain in Drosophila (Kramerova and Kramerov 1999). There is also a single report of somatic intercellular bridges seen by electron microscopy in mammals, but the authors caution that it may be the result of a tissue preparation artifact (Witkin et al. 1995).

Brill et al. (2000) used Drosophila spermatocytes to screen for cytokinesis-defective mutations, because mutants with failure of cytokinesis in meiosis are easily identified by their sterility and multinucleated spermatids. 
Nineteen genes were identified, including 16 novel loci and three known cytokinesis genes. The mammalian homolog is given, if known. However, detailed mapping of the mutated genes was not performed, so the actual gene products were not all identified. The mutants blocked cytokinesis at several stages (Fig. 1B) (Brill et al. 2000). Two mutants, diaphanous (dia, Diaphanous homolog) and pebble ( $p b l$, ECT2/RhoGEF homolog), prevent formation of the actin and anillin rings in early telophase. Five of the mutants, scapolo (scpo), celibe (cbe), james bond (bond), sauron (sau), and smeagol (sgo), affect the central spindle and the F-actin ring, but do not prevent anillin accumulation at the equator. Ten genes, four score ( $\left.f_{s c o}\right)$, brunelleschi (bru), ciambella (cia), four way stop (fws, Cog5 homolog), funnel cakes (fun), omelette (omt), onion rings (onr), four wheel drive ( $f w d$, a phosphatidylinositol 4-kinase), and giotto (gio), are primarily required for constriction of the F-actin ring. Lastly, bird's nest soup (bns) was required for actin ring disassembly. It is unclear if any of these genes are specifically involved in intercellular bridge formation. The effect on spermatogonial intercellular bridges in these mutants was not reported, but it can be inferred that the phenotypes were specific for spermatocytes. The fact that the known genes, dia, $p b l$, fwd, and $f w s$, have previously been implicated in cytokinesis further supports the model that male Drosophila intercellular bridges are composed of cytokinesis proteins.

Female Drosophila intercellular bridges are required even after the oocyte is specified. Intercellular bridges connecting the 15 nurse cells to the oocyte grow dramatically in size from $<1$ $\mu \mathrm{m}$ to $\sim 10 \mu \mathrm{m}$ as the egg chamber matures (Cooley 1998). The asymmetric division of the fusome required for oocyte specification also causes microtubules to become polarized with their minus ends directed at the oocyte (Grieder et al. 2000). These modifications allow the ring canals to transfer several cytoplasmic components from the nurse cells to the oocyte, increasing its size. For example, oocyte-specific proteins and mRNAs (e.g., Bicoid D [Mische et al. 2007] and oskar [Huynh and St Johnston 2004]) are concentrated in the oocyte. The centrosomes from the nurse cells are inactivated and transferred to the oocyte (Bolivar et al. 2001), and mitochondria are also concentrated in the oocyte (Cox and Spradling 2003).

As in males, the first evidence of female Drosophila intercellular bridge formation is an increase in phosphotyrosine epitopes (Fig. 1D) (Robinson and Cooley 1996). The phosphotyrosines are seen as $0.5-1-\mu \mathrm{m}$ rings in the stalled cleavage furrows at the end of the third mitosis (Robinson et al. 1994). The development of female intercellular bridges is known to require the convergence of cytoskeletal and kinase signaling pathways not regularly involved in cytokinesis (Fig. 1F) (Cooley 1998). First, consider the cytoskeletal pathway (Fig. 1F). By the fourth division hu-li tai shao (Hts) (Robinson et al. 1994) and additional filamentous actin (Tilney et al. 1996) localize to the inner rim of the intercellular bridge (Fig. 1D). Over the next few hours Kelch is added to the inner rim (Robinson et al. 1994), while anillin is removed from the outer rim of the intercellular bridge, and the bridge's diameter increases to 3-4 $\mu \mathrm{m}$ (Robinson and Cooley 1997). At this point, the bridges are considered "mature," but will continue to increase in diameter. Incorporation of Hts, Kelch, and filamentous actin all depend on cheerio (the mammalian filamin homolog), an actin cross-linking protein. Other proteins involved in actin dynamics such as the Arp2/3 complex (Hudson and Cooley 2002), Cortactin (Somogyi and Rorth 2004), and Akap200 (Jackson and Berg 2002) have also been shown to regulate the intercellular bridge cytoskeleton.

Kelch is able to dimerize through its BTB domain and bind to actin with its Kelch repeat domain (Robinson and Cooley 1997). It may therefore serve as an actin cross-linking protein in the growing intercellular bridge (Robinson and Cooley 1997). Kelch mutant females are sterile, but otherwise the flies are completely normal (Robinson et al. 1994). Loss of Kelch causes disorganization of the actin filaments of the intercellular bridge preventing cytoplasm transport from the nurse cells to the oocyte (Robinson et al. 1994). The kelch gene produces a single transcript separated into two open reading frames by a stop codon. Although both the 
M.P. Greenbaum et al.

truncated, ORF1, and full-length versions of the protein are expressed by tRNA suppression of the stop codon, and both proteins are in the intercellular bridge. Oddly, ORF1 is sufficient to fully rescue the kelch intercellular bridge phenotype but full length is not.

Kelch is one protein in which the kinase regulatory pathway converges with the cytoskeletal pathway (Fig. 1F). The ability for Kelch to organize actin is regulated by the Drosophila Src nonreceptor tyrosine kinase homolog Src64. Src64 is does not effect the localization of Hts of Kelch, but its kinase activity is required for expansion of the intercellular bridge diameter (Dodson et al. 1998). Src64 signaling is required for phosphorylation of Kelch at tyrosine 627 (Kelso et al. 2002). Using site-directed mutagenesis, KelchY627A is able to rescue the actin disorganization phenotype of kelch mutant intercellular bridges, but the bridges fail to expand, phenocopying the src64 mutant phenotype. Actin monomer exchange is also greatly reduced with KelchY627A. These results suggest that a major function of Src64 signaling is negative regulation of actin cross-linking by Kelch (Kelso et al. 2002).

Although Src64 is required for the phosphorylation of Kelch, it may not be the kinase that actually phosphorylates the protein. Mutations of another nonreceptor tyrosine kinase, Tec29, phenocopies the Src64 intercellular bridge phenotype (Roulier et al. 1998). Tec29 localizes to the intercellular bridge. Although Src64 does not localize to the intercellular bridge, it interacts with Tec29, and Src64 activity is required for Tec29 localization (Roulier et al. 1998; Lu 2004; Lu et al. 2004). The loss of either kinase results in a dramatic decrease in phosphotyrosine epitopes in the intercellular bridge. Although Tec29 may be the kinase that regulates Kelch, the only function currently known for Tec29 kinase activity is the creation of phosphotyrosine binding sites on unidentified intercellular bridge substrates for its own SH2 domain (Lu et al. 2004).

This overview of male and female Drosophila intercellular bridges shows that, although essential for fertility in both genders, they form by very different mechanisms. Mammalian intercellular bridges were also initially thought to have an essential role in fertility for both genders. The next section will review the current understanding of mammalian germ cell cysts.

\section{MAMMALIAN INTERCELLULAR BRIDGES}

Until 1955, the term "intercellular bridge" referred to short processes that appeared to connect squamous epithelial cells (Fawcett 1961). Electron microscopy has since shown that these structures are actually desmosomes, not true cytoplasmic connections between cells. As reviewed by Dym and Fawcett (1971), as early as 1865 LaValette St. George teased apart fresh testis and noticed that cells were able to divide, yet remain connected in a chain. Later observations by Sertoli (1877) (Fig. 2A) and von Ebner (1888) (Fig. 2B) described spermatogonia connected by processes. It was not until 1955 when electron microscopy studies examining the fine structure of cat spermatids defined the intercellular bridge as a stable cytoplasmic channel connecting cells (Fawcett et al. 1959). Shortly after, intercellular bridges were found in many animals including Hydra, fruit fly, opossum, pigeon, rat, hamster, guinea pig, rabbit, monkey, and man (Fawcett et al. 1959).

Intercellular bridges have become the basis for describing early stages of spermatogenesis. A widely used model of spermatogenesis is based on the work of Huckins (1971) and Oakberg (1971). Male germ cells start as diploid spermatogonia, proceed through meiosis as spermatocytes, and complete development as haploid spermatids. The complete process involves nine to 11 spermatogonial divisions (Huckins 1971; de Rooij and Russell 2000; Chiarini-Garcia and Russell 2002) plus two meiotic divisions. Each division results in the formation of an intercellular bridge (Weber and Russell 1987), and spermatogonia are initially classified by their intercellular bridges. The nomenclature for spermatogonial development is as follows:

$$
\begin{aligned}
\mathrm{A}_{\mathrm{s}} & \rightarrow \mathrm{A}_{\mathrm{pr}} \rightarrow \mathrm{A}_{\mathrm{al}} \text { (multiple rounds) } \rightarrow \mathrm{A}_{1} \\
& \rightarrow \mathrm{A}_{2} \rightarrow \mathrm{A}_{3} \rightarrow \mathrm{A}_{4} \rightarrow \mathrm{In} \rightarrow \mathrm{B} .
\end{aligned}
$$



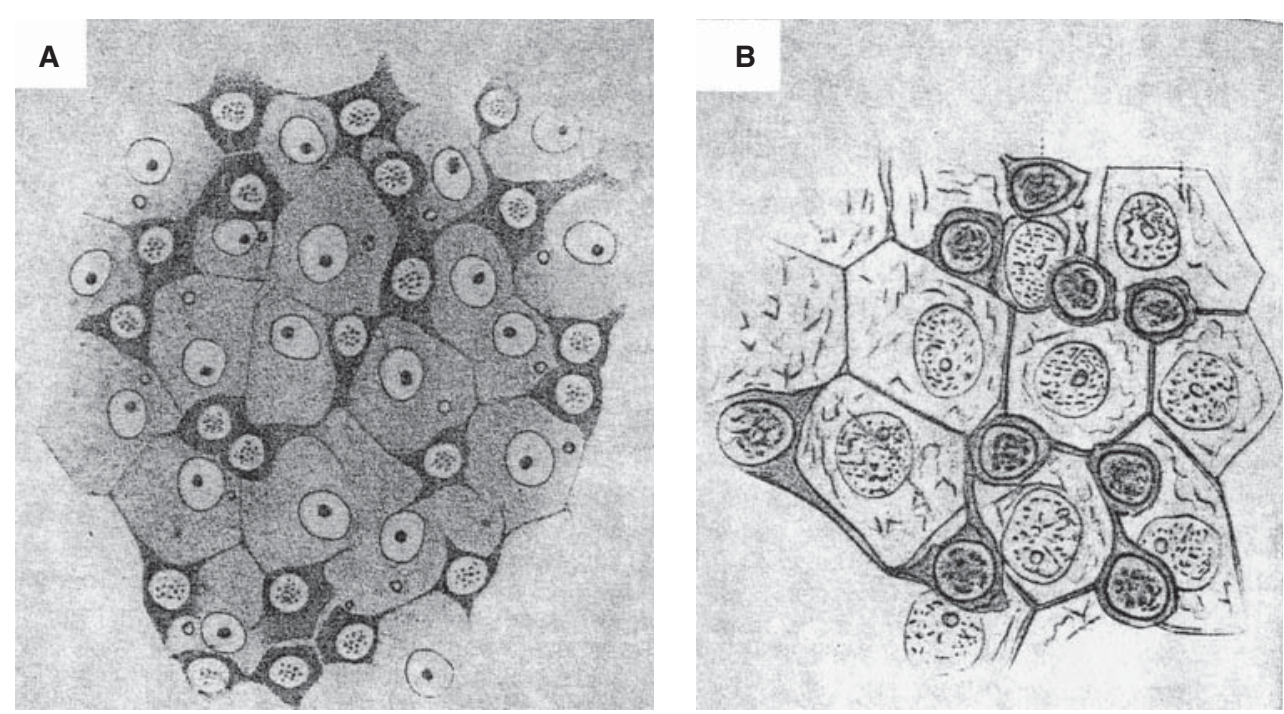

C
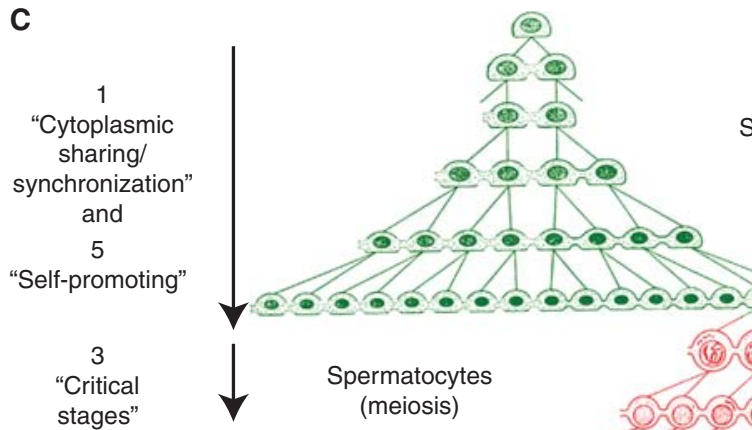

stages"
2
"Phenotypically
diploid"
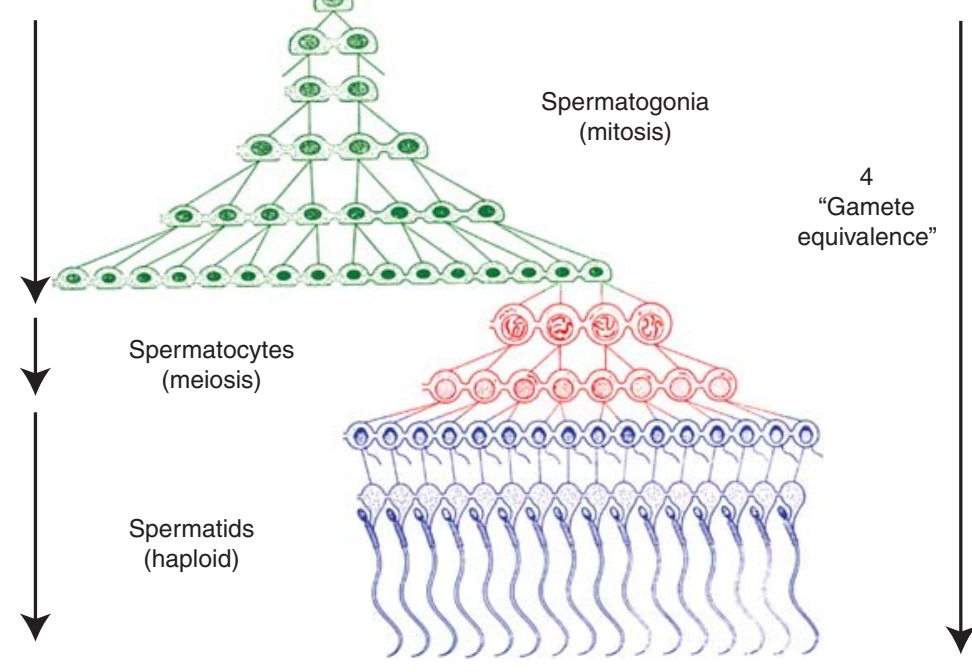

Figure 2. Mammalian intracellular bridges. Nineteenth-century sketches of intercellular bridges. Observations by Sertoli (1877) (A) and von Ebner (1888) (B) show darker staining spermatogonia connected by intercellular bridges. The lightly staining cells are Sertoli cells. $(C)$ Overview of proposed models for intercellular bridge function. Each model specifies a particular period when intercellular bridges are necessary. The "cytoplasmic sharing" and "self-promoting" models involve all dividing cells, spermatogonia, and spermatocytes. The "phenotypically diploid" model involves haploid postmeiotic cells. The "critical stage" model addresses entry into meiosis. The "gamete equivalence" could involve any stage of spermatogenesis. ( $C$, Adapted from Dym and Fawcett 1971; reprinted with permission from Society for the Study of Reproduction (C) 1971.)

The A type single $\left(A_{s}\right)$ spermatogonium is the stem cell for spermatogenesis and is the only dividing male germ cell without intercellular bridges. A single mouse testis is thought to contain about $35,000 \quad \mathrm{~A}_{\mathrm{s}}$ spermatogonia (Tegelenbosch and de Rooij 1993). The $A_{s}$ cell differentiates by dividing into A type paired $\left(A_{p r}\right)$ spermatogonia. $A_{p r}$ spermatogonia divide to form a chain of four A type aligned $\left(\mathrm{A}_{\mathrm{al}}\right)$ spermatogonia, and $A_{a l}$ spermatogonia can go through multiple rounds of division before differentiating into $A_{1}$ spermatogonia (Huckins 
M.P. Greenbaum et al.

1971; de Rooij and Russell 2000). The remaining stages through intermediate and B type spermatogonia link mitotic division with progression to the next stage. This process theoretically leads to syncytia joining thousands of cells (Moens and Hugenholtz 1975; de Rooij and Russell 2000). In practice, up to 650 cells have been observed in a single syncytium (Ren and Russell 1991).

The different stages of spermatogonia can be defined by a skilled examiner by their appearance and morphology in light (Huckins 1971; Chiarini-Garcia et al. 2001) and electron microscopy (Chiarini-Garcia and Russell 2002). Early stages of spermatogonia, such as $A_{s}$, are most easily identified in whole mounted tubules. The examiner focuses on the basal plane, where the least differentiated cells lie (Clermont and Bustos-Obregon 1968). $A_{s}$ cells are identified when no other A type spermatogonia is within $25 \mu \mathrm{m}$ of the cell. $A_{s}, A_{p r}$ and $A_{a l}$ spermatogonia can also be identified with the molecular markers such as promyelocytic leukemia zinc finger (PLZF), a protein required for spermatogonial stem cell self-renewal (Buaas et al. 2004).

The morphology of intercellular bridges has been studied exhaustively by microscopy (e.g., Burgos and Fawcett 1955; Fawcett et al. 1959; Dym and Fawcett 1971; Moens and Hugenholtz 1975; Huckins and Oakberg 1978; Weber and Russell 1987; Ren and Russell 1991; Ventela et al. 2003). The diameter of the bridge ranges in size starting at under $1 \mu \mathrm{m}$ in spermatogonia, $1-1.3 \mu \mathrm{m}$ in intermediate and B type spermatogonia, $1.4-1.7 \mu \mathrm{m}$ in spermatocytes, $1.8 \mu \mathrm{m}$ in step 1 spermatids, $3 \mu \mathrm{m}$ in step 18 spermatids, and then shrinking slightly to $2 \mu \mathrm{m}$ in step 19 spermatids (Weber and Russell 1987). By electron microscopy, a prominent electron dense "bridge density" ranging from $30-60 \mathrm{~nm}$ in thickness lines the walls of the intercellular bridge. In cytokinesis, the bridge density begins to form on the inner edge of the cleavage furrow during ingression. A midbody with normal appearance forms and then breaks down with the central spindle, leaving the intercellular bridge and the lining bridge density (Weber and Russell 1987).

Several roles for mammalian intercellular bridges in spermatogenesis have been proposed
(Fig. 2C) (Guo and Zheng 2004). Two hypotheses have the most support. The first hypothesis is that intercellular bridges permit "cytoplasmic sharing" of essential signals for the synchronous cell divisions seen in longitudinal segments of seminiferous tubules (Fawcett et al. 1959; Huckins and Oakberg 1978; Ren and Russell 1991). In this untested model, synchronization is proposed to play an essential role in progression through spermatogenesis. A second hypothesis points out that intercellular bridges may be necessary for haploid germ cells to remain "phenotypically diploid” after meiosis (Fawcett et al. 1959; Erickson 1973; Braun et al. 1989). The most extreme example of this would be for genes with only one copy (e.g., genes on the sex chromosomes). Supporting this second hypothesis, mRNA expressed from a single copy transgene encoding human growth hormone (hGH) under the control of the protamine 1 regulatory sequences was observed to distribute evenly in haploid spermatids (Braun et al. 1989). The protein product was also found equally distributed among the spermatids. In a nontransgenic example, the testis brain RNA-binding protein (TB-RBP) functions as an RNA-binding protein in the testis and binds to Akap4 mRNA. Akap4 is an X-linked gene essential for sperm motility and fertility (Miki et al. 2002). Akap4 mRNA forms a complex with TB-RBP and the Ter ATPase and passes through intercellular bridges between spermatids (Morales et al. 2002). Additionally, because of the large size of intercellular bridges, even organelles (Ventela et al. 2003) have been observed to move between haploid spermatids.

A second hypothesis proposes that intercellular communication between germ cells occurs at "critical stages," such as coordinating the entry into meiosis (Stanley et al. 1972; Robinson and Cooley 1996). In this model, the event is coordinated by the "rapid" transfer of an unidentified signal/substance through the syncytium. A third hypothesis is that intercellular bridges create "gamete equivalence" and would thus result in a more uniform population of sperm which, overall, would be of higher quality (Guo and Zheng 2004). A final hypothesis is that intercellular bridges allow for the 
elimination of cells with "self-promoting genes" (LeGrand 2001). In this model, a mutation exists which would give a selective advantage to the mutated gamete but would be detrimental to future progeny. For example, the cell could have uncontrolled and greatly increased cell proliferation and have a mutation in a gene required for apoptosis. Normally functioning cells in the syncytium detect something is wrong through the intercellular bridges and the problem is eliminated by apoptosis of the entire cyst. Of course, because all the cells are clonally related, the mutation would have to be acquired somehow after the initial $A_{s}$ cell division.

To test these hypotheses requires manipulation of the intercellular bridge. The molecular mechanism of mammalian intercellular bridge formation is a recent area of study. The protein TEX14 is expressed specifically in germ cells and localizes to the intercellular bridge in mice (Greenbaum et al. 2006) and humans (Fig. 3A) (Greenbaum et al. 2007). The protein contains three amino-terminal ankyrin repeats, centrally is a dead-kinase domain, and the remainder contains coiled-coil motifs. Interestingly, when compared by BLAST analysis to the Drosophila genome, the dead-kinase domain bears more resemblance to src64 and tec29 (see above) than any other kinases.

Knockout of mouse Tex14 eliminates the formation of intercellular bridges (Greenbaum et al. 2006) and results in male infertility. It was found that without intercellular bridges spermatogenesis fails to complete meiosis. In fact, molecular studies showed that only a very small number of spermatocytes make it to pachytene. Importantly, this result proved that intercellular bridges are not required for the transit amplification of germ cells from the $A_{s}$ stem cells spermatogonia through the initiation of meiosis.

Although it is clear completion of meiosis during spermatogenesis requires intercellular bridges, the exact role of the intercellular bridge remains unknown. Many of the proposed roles listed above may be relevant. Perhaps intercellular bridges do allow passage of a signal for entering the "critical stage" of meiosis through an

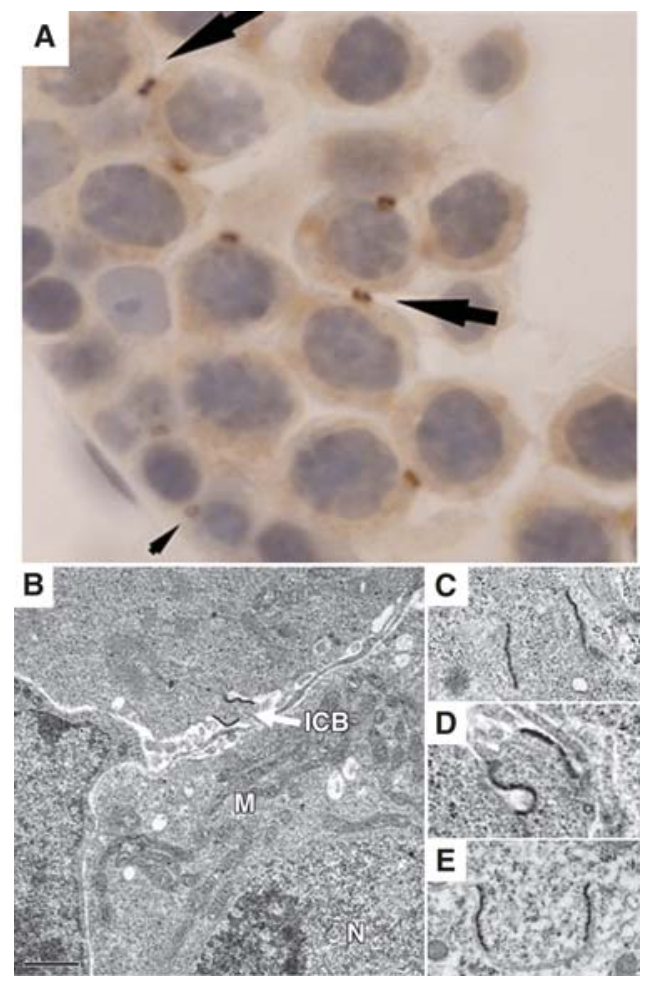

Figure 3. TEX14 is a critical component of mammalian intracellular bridges. (A) Immunohistochemical staining of control testes using anti-TEX14 antibody labels ring-shaped structures (arrows) that are absent from TEX14 null germ cells. (B-E) Electron microscopy reveals electron dense material lining cytoplasmic channels between newborn ovarian germ cells. No intercellular bridges were found in knockout ovaries. ICB, intercellular bridge; $\mathrm{M}$, mitochondria; $\mathrm{N}$, nucleus.

unknown mechanism. Interestingly, mammalian somatic cells die through a p53-dependent mechanism if they fail to complete cytokinesis (Postiglione et al. 2009). For germ cells, incomplete cytokinesis is the norm and it is completion that results in increased apoptosis (Greenbaum et al. 2006). The one function intercellular bridges are known to play, passage of RNA material in haploid cells, could not be evaluated because no germ cells progressed through meiosis. Thus, intercellular bridges are required for spermatogenesis but their essential role remains undiscovered.

Embryonic mammalian male (Gondos and Hobel 1971; Fukuda et al. 1975) and female 
M.P. Greenbaum et al.

(Gondos et al. 1971; Pepling and Spradling 1998, 2001; Pepling et al. 1999) germ cells are also connected by intercellular bridges. Mitotic division of germ cells occurs for a finite period during embryogenesis in mammals. Germ cell division in the embryonic ovary is synchronized, presumably through intercellular bridges (Pepling and Spradling 1998). In female mice, germ cells enter meiosis around E14.5 (Borum 1961; Pepling and Spradling 1998). No divisions occur beyond meiosis, so no new intercellular bridges form beyond embryogenesis. Female germ cell cysts break down over the second through fourth day after birth (Pepling and Spradling 2001) leaving single oocytes to form primary follicles. Similar to Drosophila, intercellular bridges have been proposed to allow "nurse cells" to promote oocyte development (Pepling and Spradling 2001). Supporting this idea in mice, mitochondria have been shown to reorganize and increase in number around the time of birth (Pepling et al. 1999; Pepling and Spradling 2001). In males, newborn mouse prospermatogonia migrate and arrive at the seminiferous tubule basement membrane within the first few postnatal days (McGuinness and Orth 1992). Mitosis resumes at postnatal day three when mitotic figures are seen in 10\% of the prospermatogonia before reaching the basement membrane (Nebel et al. 1961; McGuinness and Orth 1992).

The Tex14 knockout mice were used to evaluate the role of embryonic intercellular bridges. Tex14 was found to localize to embryonic bridges and intercellular bridges seemed to be absent in Tex14 knockouts by electron microscopy (Fig. 3B). Still, a second method of confirmation was desired to show the bridges were truly not present. Immunofluorescence is the best way to look at a large amount of tissue for intercellular bridges, but there were no other known embryonic bridge components. A biochemical approach was taken to find more components of the intercellular bridge (Greenbaum et al. 2007). Testis bridges were used because they were more abundant and easier to obtain. Several new components were identified, and the order in which they joined and left the intercellular bridge could be followed in newborn testis. Using one of these new intercellular bridge markers it was confirmed by immunofluorescence that the embryonic intercellular bridges were gone.

Surprisingly, Tex14 knockout females remained fertile without intercellular bridges! This was not the case in Drosophila in which intercellular bridges play a well-described critical role in fertility (see above). Apparently, despite a billion years of conservation, female intercellular bridges are not essential. That is not to say they do not play an important function. It is obvious that selective pressures exist in nature that are absent in a controlled laboratory environment. However, there is a possibility that the female bridges exist as a vestigial structure purely because of the essential role intercellular bridges play in spermatogenesis.

\section{A SPECIAL FORM OF CYTOKINESIS}

A typical description of cytokinesis is presented as, "Cytokinesis is the final process in cell division through which one cell is separated into two daughter cells." Clearly, this is not the best definition for a section whose central topic is intercellular bridges, the stable cytoplasmic connection joining the daughter cells. Nonetheless, it is important to describe the basic principles of cytokinesis, as intercellular bridge formation is a modification of how the vast majority of cells divide. Although the most dramatic event of cytokinesis in mammalian cells is ingression of the cleavage furrow, this single event is not the whole picture. The process of cytokinesis can be divided into at least three broad stages as follows: (1) selecting the site of cell division (Burgess and Chang 2005), (2) furrow ingression and formation of a contractile ring (Matsumura 2005; Wang 2005), and (3) abscission of the midbody (von Dassow and Bement 2005). Although the end result of this process, cell separation, is the same in all eukaryotic organisms, there are several variations on the theme (Guertin et al. 2002), with plants even replacing the processes of furrow formation and ingression with a cytoskeletal/ vesicular framework called the phragmoplast (Otegui et al. 2005). For our purpose, the 
following section, when possible, will review the mechanism of cytokinesis as it relates to mammalian cells. Furthermore, although early events in cytokinesis will be addressed briefly, the greatest focus will be on the late events of cytokinesis, as these directly relate to intercellular bridge formation.

Early in cytokinesis, it is necessary to select the site of cell division. In animal cells, the region where the cleavage furrow will form is specified by the microtubules of the mitotic apparatus at the onset of anaphase. This linkage to the mitotic apparatus provides the necessary coordination of chromosomal segregation with cell division. The cleavage site forms at the former metaphase plate, bisecting the two centrosomes. Microtubule depolymerization studies and manipulation of the spindle apparatus (Rappaport 1986; Rieder et al. 1997) show that the mitotic spindle somehow signals to the cortex to determine the region where the cleavage furrow will form. Despite more than a hundred years of study pioneered by Ray Rappaport (Canman and Wells 2004), most aspects of the signaling process remain unknown (Burgess and Chang 2005). Both the signal and the region of the mitotic apparatus that emits the signal remain to be identified. Although many models have been proposed (Canman and Wells 2004; Burgess and Chang 2005), they each have drawbacks. The mechanism of cleavage furrow site selection seems distinct from intercellular bridge formation because it is an early event in cytokinesis that occurs normally in mammalian germ cells. For this reason, these models will not be discussed in further detail.

Furrow ingression follows site selection. The predominant model for the process of furrow formation is the contractile ring hypothesis (Satterwhite and Pollard 1992). This process is very similar in yeast and animal cells, which both divide using an actomyosin contractile ring. Actin and myosin II assemble in a ring around the perimeter of the putative cleavage site. Like a contracting myofiber, antiparallel actin filaments slide together through the action of myosin II resulting in contraction of the ring. The process often draws comparison to a "purse string" as it squeezes the plasma membrane
(Wang 2005). The contraction of the equatorial membrane generates enough force to bend a flexible microneedle (Rappaport 1967). As in cleavage site selection (above), the mitotic spindle (now called the central spindle or spindle midzone during furrowing) is generally accepted to regulate cleavage furrowing (Matsumura 2005).

Several evolutionarily conserved complexes essential for cytokinesis have been identified in the central spindle (Glotzer 2005). These are the Aurora B-INCENP-CSC1-Survivin complex, the PRC1-KIF4 complex, the ECT2/ RhoGEF (Glotzer 2005), and the mitotic kinesin-like protein 1 (MKLP1)-Male germ cell Rac GTPase-activating protein (MgcRacGAP) complex (also called centralspindlin) (Mishima et al. 2002). Loss of any of these complexes causes cytokinesis failure. It should be pointed out that the name MgcRacGAP (Male germ cell Rac GTPase-activating protein) is somewhat misleading. Although originally described as having predominantly male germ cell expression (Toure et al. 1998), like MKLP1, it is ubiquitously expressed and required for cytokinesis in all cells. Accordingly, MgcRacGAP homozygous gene trap mice die during preimplantation development with multinucleated blastomeres and a dramatic decrease in cell number at day E3.5 because of cytokinesis failure (Van de Putte et al. 2001).

The completion of furrow ingression forms a transient intercellular bridge called the midbody, which connects the daughter cells at the end of cytokinesis. Germ cells form intercellular bridges by altering the fate of the midbody. Rather than discard the transient intercellular bridge by abscission, it is modified into a permanent structure. The composition of the midbody matrix contains several of the conserved complexes mentioned previously (Glotzer 2005). In particular, the centralspindlin complex (Mishima et al. 2002), MKLP1 (Matuliene and Kuriyama 2004), and MgcRacGAP (Arar et al. 1999), is essential for forming the midbody matrix. RNA interference (RNAi) against MKLP1 in mammalian cells prevents formation of a normal midbody matrix resulting in 
M.P. Greenbaum et al.

unstable midbodies and failure of cytokinesis (Matuliene and Kuriyama 2004). MKLP1 in the midbody exists in a complex with 1-to-1 stoichiometry with MgcRacGAP, and this complex, centralspindlin, has been reconstituted and shown to bind microtubules in vitro (Mishima et al. 2002). It also indirectly recruits components needed for abscission.

Abscission is the final process in cytokinesis by which the midbody is removed to achieve truly individual cells. Compared to cleavage furrow ingression, which takes $\sim 20 \mathrm{~min}$, abscission is a relatively slow process, requiring 1-3 h to complete (von Dassow and Bement 2005). At least two processes are necessary to achieve abscission. First, the organization of the matrix in the middle of the midbody forms a central ring. By light microscopy, this structure is called the Flemming body, a slightly bulging region right in the middle of the midbody. The formation of the midbody ring is followed by membrane fusion events to cleave the midbody (von Dassow and Bement 2005). Many of the proteins required in these processes have been identified (Gromley et al. 2003, 2005; Low et al. 2003).

There are several vesicle-associated proteins whose essential role in abscission has been identified. The first identified proteins of this class were syntaxin 2 and endobrevin (Low et al. 2003), members of the soluble NSF attachment receptor (SNARE) complex required for SNARE mediated membrane fusion events (Hanson et al. 1997). Syntaxin 2 and endobrevin colocalize laterally to the midbody matrix. RNAi showed that both proteins are essential for abscission of the midbody in HeLa cells (Low et al. 2003).

The identification of other trafficking proteins came, surprisingly, from studying centrosomal proteins. Centriolin, initially known only as a centrosome component, was found to localize to the midbody of HeLa cells (Gromley et al. 2003). RNAi of centriolin did not lead to a microtubule defect but resulted in a novel cytokinesis phenotype (Gromley et al. 2003). Rather that form multinucleated cells, as seen in previous cytokinesis defects, loss of centriolin caused long, thin intercellular bridges to remain connecting the daughter cells. Further studies showed that the SNARE proteins, syntaxin 2, endobrevin, and snapin, require centriolin for localization (Gromley et al. 2005). The exocyst complex (Hsu et al. 2004) is required for vesicle mediated secretion and also plays a role in abscission. Centriolin is also required for localization of the exocyst complex to the midbody. Exocyst complex proteins sec3, sec5, sec8, sec15, and exo84 failed to localize to the midbody in centriolin RNAi knockdown experiments (Gromley et al. 2005). Another centrosomal protein, centrosome protein $55 \mathrm{kDa}$ (CEP55), was found to localize to the midbody matrix in somatic cells (Fabbro et al. 2005; Martinez-Garay et al. 2006). CEP55 was found to bind to the centralspindlin complex (Zhao et al. 2006). Deficiency of CEP55 leads to arrest at the midbody stage in somatic cells and formation of multinucleated cells (Carlton and Martin-Serrano 2007; Morita et al. 2007). In addition, knockdown of the direct downstream interacting partners of CEP55 such as ESCORT-1 (endosomal sorting complex required for transport-1) or ALIX (ALG-2 interacting protein $\mathrm{X}$, also known as programmed cell death 6 interacting protein or PCD6IP), leads to a similar phenotype (Carlton and Martin-Serrano 2007; Morita et al. 2007). These studies suggest that these interactions are essential for somatic cell abscission (Carlton and Martin-Serrano 2007; Morita et al. 2007; Carlton et al. 2008).

\section{FORMATION OF THE STABLE INTERCELLULAR BRIDGE}

Knockout of mouse Tex14 showed that the formation of stable intercellular bridges is essential for spermatogenesis and fertility (Greenbaum et al. 2006). However, until quite recently, it remained unclear how TEX14 participated in stable intercellular bridge formation to prevent abscission and the completion of cytokinesis in male germ cells.

CEP55 was identified as a component of stable intercellular bridges, and is perfectly colocalized with TEX14 as ring-shaped intercellular bridge structures in germ cells throughout 
the seminiferous tubules at all stages of spermatogenesis. The bridge diameter expands from the juvenile to the adult stage, suggesting that additional factors such as CEP55 and TEX14 are added to the stable intercellular bridge during spermatogenesis. In the female, CEP55 is expressed and colocalized with TEX14 in the embryonic 18.5-day-old mouse ovary.

In somatic cells, abscission requires CEP55, ALIX, and TSG101 (a component of the ESCRT complex). CEP55 is recruited from the centrosome to the midbody and interacts with MKLP1 (Fabbro et al. 2005; Martinez-Garay et al. 2006; Zhao et al. 2006). Furthermore, CEP55 forms homodimers through coiledcoil interactions, and subsequently, ALIX and
TSG101 are recruited to the midbody by binding the "hinge" region of CEP55 (Fig. 4, lower panel) (Martinez-Garay et al. 2006; Carlton and Martin-Serrano 2007; Morita et al. 2007). Glycine (G)-proline (P)-proline (P)-X-X-Xtyrosine (Y) (GPPX3Y) motifs in ALIX and TSG101 are critical for this interaction with the "hinge" region of CEP55 (Morita et al. 2007; Lee et al. 2008). CEP55 was also identified as a TEX14 interactor (Iwamori et al. 2010). Nineteen TEX14 orthologs contain a GPPX3Y, which mimic the ALIX and TSG101 interactions with CEP55 (Iwamori et al. 2010; Wang et al. 2001; Wu et al. 2003). Although there is significant divergence of these orthologs in their carboxy-terminal regions compared to the

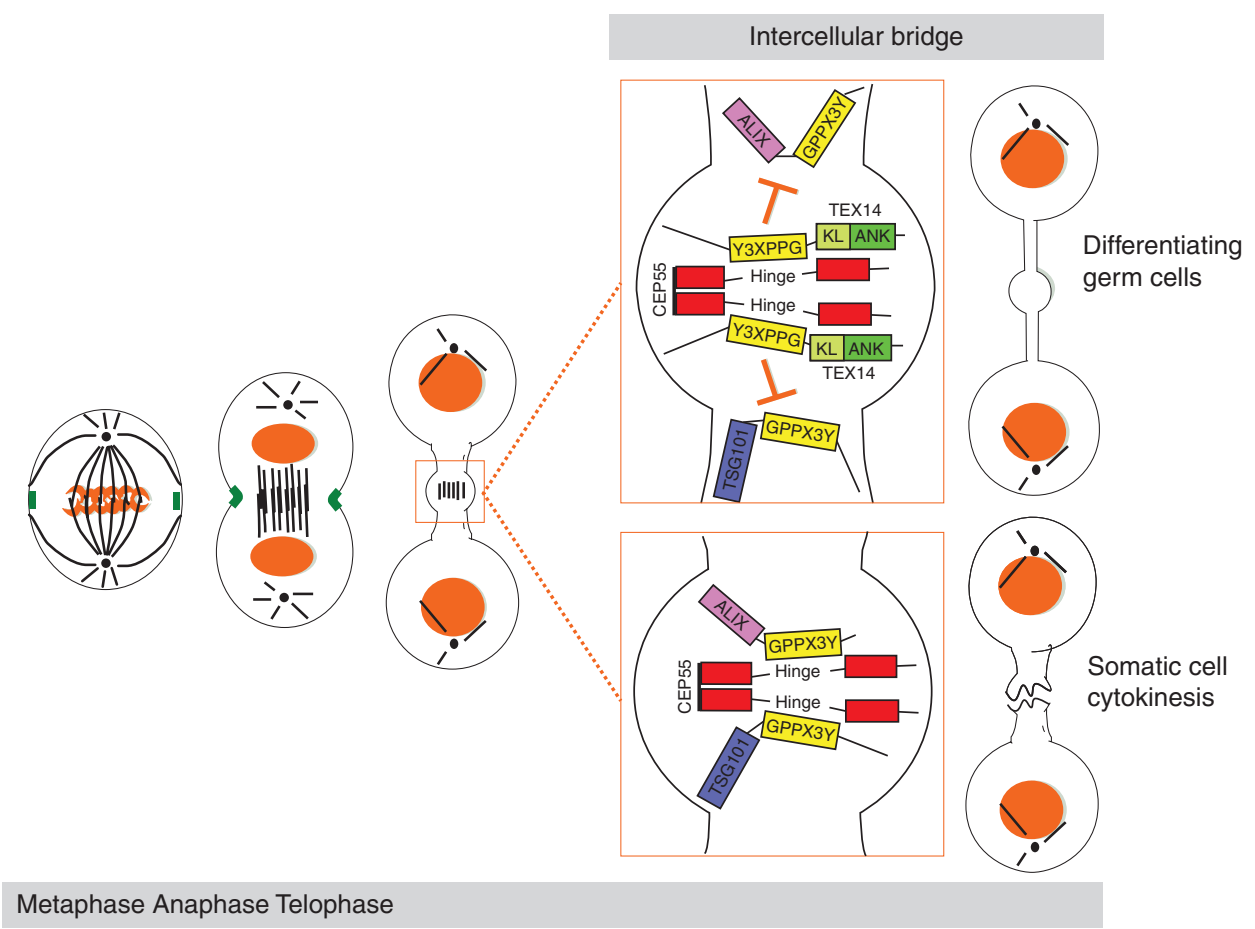

Figure 4. Stable intercellular bridge formation requires TEX14 disruption of interactions between CEP55 and other cytokinesis components. During mitosis, the contractile ring (green) is established adjacent to the metaphase plate. At anaphase, spindle microtubules assume a bipolar orientation (central spindle). In telophase, somatic cells (left lower box), a complex is assembled at the midbody (red open box) composed of ALIX (blue box) and TSG101 (pink box) bound to the hinge region of CEP55 (red box) through their GPPX3Y domains, resulting in abcission. In contrast, in differentiating germ cells the hinge region of CEP55 instead interacts with TEX14 and forms a stable ring-like structure, potentially excluding ALIX and TSG101 from the midbody and preventing abscission. KL, kinase-like domain; ANK, ankyrin domain. 
M.P. Greenbaum et al.

ankyrin repeats (ANK) and kinase-like (KL) domains in their amino termini, 17 of the 19 proteins share a similar GPPX3Y motif in their carboxy termini, with the exceptions being the Xenopus laevis and dolphin orthologs. In addition, several additional amino acids are conserved between TEX14 and other GPPX3Ycontaining proteins including an alanine upstream of the GPPX3Y motif (also present in human ALIX and TSG101), serine/threonine/alanine within the motif, and two prolines downstream (one also present in TSG101). We hypothesize the GPPX3Y motif of TEX14 binds strongly to CEP55 to block similar GPPX3Y motifs of ALIX and TSG101 preventing their interaction with CEP55 and localization to the midbody (Fig. 4, upper panel). In particular, the first proline and the tyrosine of the GPPX3Y motif were sufficient for this portion of TEX14 to interact with CEP55. The exogenous expression of TEX14 in cell culture precludes ALIX from the midbody and produces interconnected somatic cells. By binding endogenous CEP55 and blocking ALIX and TSG101 from interacting with CEP55, TEX14 inhibits the completion of cytokinesis and stabilizes the transient intercellular bridge. This shifts the role of CEP55 from a midbody organizer that recruits proteins for abscission to the midbody to a major component in the stable intercellular bridge. TEX14:CEP55 complexes are critical for the formation of stable intercellular bridges.

In general, abscission can be described as MKLP1 $\rightarrow$ CEP55 $\rightarrow$ ALIX/TSG101 $\rightarrow \rightarrow \rightarrow$ abscission; however, in differentiating male (and presumably female) germ cells, the steps involved appear to be MKLP1 $\rightarrow$ TEX14 $\rightarrow$ CEP55 $\rightarrow$ intercellular bridge. The fact that TEX14 appears early in the process of cytokinesis bound to MKLP1 and filling the intercellular bridge (Greenbaum et al. 2007) may allow TEX14 to compete for CEP55 more effectively. In testes of TEX14 null mice, CEP55 localizes to the midbody by binding MKLP1 and, in the absence of local TEX14, its interaction with ALIX and TSG101 is permitted. Complete cytokinesis occurs, disrupting the transient intercellular bridge, and resulting in an eventual failure of spermatogenesis during meiotic prophase (Greenbaum et al. 2006).

\section{OTHER MAMMALIAN INTERCELLULAR BRIDGE FUNCTIONS}

Recently our group identified a second testisabundant component of the mammalian intercellular bridge, RBM44 (RNA binding motif 44), through its association with TEX14 (Iwamori et al. 2011). RBM44 is not, however, a known component of the midbody, but RBM44 orthologs are present in placental and marsupial mammals, birds, and fish. Distinct from TEX14, RBM44 does not localize to all intercellular bridges, but only to those in meiotic germ cells. Based on the presence of an RRM (RNA recognition motif) domain in RBM44 and robust immunostaining of spermatocyte cytoplasm in addition to the bridge, the protein may serve to transport mRNA, including across intercellular bridges. Furthermore, targeted disruption of Rbm44 results in an unexpected increase in sperm number without the loss of intercellular bridges. Therefore, the mechanistic role of RBM44, unlike the CEP55-TEX14 interaction, is not to physically stabilize the bridge but may be to eliminate select meiotic germ cells, perhaps as a quality checkpoint. Because physiologic apoptosis of spermatocytes predominantly occurs during the meiotic divisions, potentially by activation of the spindle checkpoint, it is notable that the peak of RBM44 staining occurs during stage XII of spermatogenesis when the meiotic divisions occur. Alternatively, the lack of infertility in RBM44 null mice may be due at least partially from redundancy with the more than 100 RRM domain-containing proteins; however, these possess little similarity to RBM44 outside the RRM domain. The RRM domain of RBM22 has the highest identity to that of RBM44, with those of RBMX, RBMXL2, RBMXRT, RBMY1A1, RBM4, RBM4B, RBM14, RBM15B, BRUNOL6, and DAZAP1 only slightly less identical. Tissue microarray data suggest that some of this group may be testisexpressed (e.g., RBM4B, RBM14) or testis-specific (e.g., RBMXL2) (UCSC genes http:// genome.ucsc.edu/). RBM22 mRNA appears to 
Intercellular Bridges

increase over ovarian follicular development, and RBM4 and RBM14 are expressed in male germ cells, with distinct kinetics (Mammalian Reproductive Genetics database http://mrg. genetics.washington.edu/). Intriguingly, RBM22 interacts with ALG-2 (Montaville et al. 2006), a binding partner of midbody protein ALIX, so TEX14 interactions with RRM domain-containing proteins could act to redundantly block ALIX entry into the midbody by a CEP55-independent mechanism.

\section{CONCLUDING REMARKS}

Additional questions remain regarding mammalian stable intercellular bridges. TEX14 knockout studies strongly support the "critical stage" hypothesis (Fig. 2C), but do not exclude the "synchronization" or "phenotypically diploid" hypotheses. The particular functions contributed by intercellular bridges essential to completion of meiotic prophase in spermatocytes have yet to be elucidated. Intercellular bridges are not essential to ovarian folliculogenesis, but whether they contribute to oocyte function or act redundantly with oocyte-specific pathways is unclear. To ensure that germ cell intercellular bridges remain stable in the face of environmental insults, additional protein interactions may be required in addition to the TEX14:CEP55 interaction, such as between TEX14 and other known or novel bridge components. Exclusion of abscission components from the midbody by the TEX14: CEP55 interaction may also indirectly affect other abscission events, such as those involving the ESCRT complex. Because TEX14 exerts such a large role in the formation of stable intercellular bridges and interacts with general abscission components, we believe that characterization of the key molecular mechanisms underpinning this germ cell-specific variation on abscission will facilitate drug therapy targeted at disrupting stabile intercellular bridges in germ cells for male contraception. Conversely, a small molecule mimic of TEX14 might be applicable as a cancer therapeutic targeted at blocking abscission in continuously proliferating cancer cells.

\section{ACKNOWLEDGMENTS}

These studies were supported in part by the Eunice Kennedy Shriver NICHD/NIH through cooperative agreements U54-HD07495 as part of the Specialized Cooperative Centers Program in Reproduction and Infertility Research, R01HD057880, and U01-HD60496 as part of the Cooperative Program in Male Contraception (to M.M.M.) and T32HD07165 (to G.M.B).

\section{REFERENCES}

Arar C, Ott MO, Toure A, Gacon G. 1999. Structure and expression of murine mgcRacGAP: Its developmental regulation suggests a role for the Rac/MgcRacGAP signalling pathway in neurogenesis. Biochem J $343 \mathrm{Pt} \mathrm{1:}$ 225-230.

Bolivar J, Huynh JR, Lopez-Schier H, Gonzalez C, St Johnston D, Gonzalez-Reyes A. 2001. Centrosome migration into the Drosophila oocyte is independent of BicD and egl, and of the organisation of the microtubule cytoskeleton. Development 128: 1889-1897.

Borum K. 1961. Oogenesis in the mouse. A study of the meiotic prophase. Exp Cell Res 24: 495-507.

Braun RE, Behringer RR, Peschon JJ, Brinster RL, Palmiter RD. 1989. Genetically haploid spermatids are phenotypically diploid. Nature 337: 373-376.

Brill JA, Hime GR, Scharer-Schuksz M, Fuller MT. 2000. A phospholipid kinase regulates actin organization and intercellular bridge formation during germline cytokinesis. Development 127: 3855-3864.

Buaas FW, Kirsh AL, Sharma M, McLean DJ, Morris JL, Griswold MD, de Rooij DG, Braun RE. 2004. Plzf is required in adult male germ cells for stem cell selfrenewal. Nat Genet 36: 647-652.

Burgess DR, Chang F. 2005. Site selection for the cleavage furrow at cytokinesis. Trends Cell Biol 15: 156-162.

Burgos MH, Fawcett DW. 1955. Studies on the fine structure of the mammalian testis. I. Differentiation of the spermatids in the cat (Felis domestica). J Biophys Biochem Cytol 1: 287-300.

Canman JC, Wells WA. 2004. Rappaport furrows on our minds: The ASCB Cytokinesis Meeting Burlington, VT July 22-25, 2004. J Cell Biol 166: 943-948.

Carlton JG, Martin-Serrano J. 2007. Parallels between cytokinesis and retroviral budding: A role for the ESCRT machinery. Science 316: 1908-1912.

Carlton JG, Agromayor M, Martin-Serrano J. 2008. Differential requirements for Alix and ESCRT-III in cytokinesis and HIV-1 release. Proc Natl Acad Sci 105: 10541-10546.

Carmena M, Riparbelli MG, Minestrini G, Tavares AM, Adams R, Callaini G, Glover DM. 1998. Drosophila polo kinase is required for cytokinesis. J Cell Biol 143: 659-671.

Chiarini-Garcia H, Russell LD. 2002. Characterization of mouse spermatogonia by transmission electron microscopy. Reproduction 123: 567-577. 
M.P. Greenbaum et al.

Chiarini-Garcia H, Hornick JR, Griswold MD, Russell LD 2001. Distribution of type A spermatogonia in the mouse is not random. Biol Reprod 65: 1179-1185.

Clermont Y, Bustos-Obregon E. 1968. Re-examination of spermatogonial renewal in the rat by means of seminiferous tubules mounted "in toto". Am J Anat 122: 237-247.

Cooley L. 1998. Drosophila ring canal growth requires Src and Tec kinases. Cell 93: 913-915.

Cox RT, Spradling AC. 2003. A Balbiani body and the fusome mediate mitochondrial inheritance during Drosophila oogenesis. Development 130: 1579-1590.

de Cuevas M, Spradling AC. 1998. Morphogenesis of the Drosophila fusome and its implications for oocyte specification. Development 125: 2781-2789.

de Cuevas M, Lee JK, Spradling AC. 1996. $\alpha$-spectrin is required for germline cell division and differentiation in the Drosophila ovary. Development 122: 3959-3968.

de Rooij DG, Russell LD. 2000. All you wanted to know about spermatogonia but were afraid to ask. J Androl 21: $776-798$.

Deng W, Lin H. 1997. Spectrosomes and fusomes anchor mitotic spindles during asymmetric germ cell divisions and facilitate the formation of a polarized microtubule array for oocyte specification in Drosophila. Dev Biol 189: 79-94.

Dodson GS, Guarnieri DJ, Simon MA. 1998. Src64 is required for ovarian ring canal morphogenesis during Drosophila oogenesis. Development 125: 2883-2892.

Dym M, Fawcett DW. 1971. Further observations on the numbers of spermatogonia, spermatocytes, and spermatids connected by intercellular bridges in the mammalian testis. Biol Reprod 4: 195-215.

Erickson RP. 1973. Haploid gene expresion versus meiotic drive: The relevance of intercellular bridges during spermatogenesis. Nat New Biol 243: 210-212.

Fabbro M, Zhou BB, Takahashi M, Sarcevic B, Lal P, Graham ME, Gabrielli BG, Robinson PJ, Nigg EA, Ono Y, et al. 2005. Cdk1/Erk2- and Plk1-dependent phosphorylation of a centrosome protein, Cep55, is required for its recruitment to midbody and cytokinesis. Dev Cell 9: 477-488.

Fawcett DW. 1961. Intercellular bridges. Exp Cell Res Suppl 8: $174-187$.

Fawcett DW, Ito S, Slautterback D. 1959. The occurrence of intercellular bridges in groups of cells exhibiting synchronous differentiation. J Biophys Biochem Cytol 5: 453-460.

Field CM, Alberts BM. 1995. Anillin, a contractile ring protein that cycles from the nucleus to the cell cortex. J Cell Biol 131: 165-178.

Fukuda T, Hedinger C, Groscurth P. 1975. Ultrastructure of developing germ cells in the fetal human testis. Cell Tissue Res 161: 55-70.

Giansanti MG, Farkas RM, Bonaccorsi S, Lindsley DL, Wakimoto BT, Fuller MT, Gatti M. 2004. Genetic dissection of meiotic cytokinesis in Drosophila males. Mol Biol Cell 15: 2509-2522.

Glotzer M. 2005. The molecular requirements for cytokinesis. Science 307: 1735-1739.

Gondos B, Hobel CJ. 1971. Ultrastructure of germ cell development in the human fetal testis. Z Zellforsch Mikrosk Anat 119: 1-20.
Gondos B, Bhiraleus P, Hobel CJ. 1971. Ultrastructural observations on germ cells in human fetal ovaries. Am J Obstet Gynecol 110: 644-652.

Gonzalez-Reyes A. 2003. Stem cells, niches and cadherins: A view from Drosophila. J Cell Sci 116: 949-954.

Greenbaum MP, Yan W, Wu MH, Lin YN, Agno JE, Sharma M, Braun RE, Rajkovic A, Matzuk MM. 2006. TEX14 is essential for intercellular bridges and fertility in male mice. Proc Natl Acad Sci 103: 4982-4987.

Greenbaum MP, Ma L, Matzuk MM. 2007. Conversion of midbodies into germ cell intercellular bridges. Developmental Biology 305: 389-396.

Grieder NC, de Cuevas M, Spradling AC. 2000. The fusome organizes the microtubule network during oocyte differentiation in Drosophila. Development 127: 4253-4264.

Gromley A, Jurczyk A, Sillibourne J, Halilovic E, Mogensen M, Groisman I, Blomberg M, Doxsey S. 2003. A novel human protein of the maternal centriole is required for the final stages of cytokinesis and entry into $S$ phase. $J$ Cell Biol 161: 535-545.

Gromley A, Yeaman C, Rosa J, Redick S, Chen CT, Mirabelle S, Guha M, Sillibourne J, Doxsey SJ. 2005. Centriolin anchoring of exocyst and SNARE complexes at the midbody is required for secretory-vesicle-mediated abscission. Cell 123: 75-87.

Guertin DA, Trautmann S, McCollum D. 2002. Cytokinesis in eukaryotes. Microbiol Mol Biol Rev 66: 155-178.

Guo GQ, Zheng GC. 2004. Hypotheses for the functions of intercellular bridges in male germ cell development and its cellular mechanisms. J Theor Biol 229: 139-146.

Hanson PI, Heuser JE, Jahn R. 1997. Neurotransmitter release-four years of SNARE complexes. Curr Opin Neurobiol 7: 310-315.

Hime GR, Brill JA, Fuller MT. 1996. Assembly of ring canals in the male germ line from structural components of the contractile ring. J Cell Sci 109: 2779-2788.

Hsu SC, TerBush D, Abraham M, Guo W. 2004. The exocyst complex in polarized exocytosis. Int Rev Cytol 233: 243-265.

Huckins C. 1971. The spermatogonial stem cell population in adult rats. I. Their morphology, proliferation and maturation. Anat Rec 169: 533-557.

Huckins C, Oakberg EF. 1978. Morphological and quantitative analysis of spermatogonia in mouse testes using whole mounted seminiferous tubules, I. The normal testes. Anat Rec 192: 519-528.

Hudson AM, Cooley L. 2002. A subset of dynamic actin rearrangements in Drosophila requires the Arp2/3 complex. J Cell Biol 156: 677-687.

Huynh JR, St Johnston D. 2004. The origin of asymmetry: Early polarisation of the Drosophila germline cyst and oocyte. Curr Biol 14: R438-449.

Iwamori T, Iwamori N, Ma L, Edson MA, Greenbaum MP, Matzuk MM. 2010. TEX14 interacts with CEP55 to block cell abscission. Mol Cell Biol 30: 2280-2292.

Iwamori T, Lin YN, Ma L, Iwamori N, Matzuk MM. 2011. Identification and characterization of RBM44 as a novel intercellular bridge protein. PLoS One 6: e17066.

Jackson SM, Berg CA. 2002. An A-kinase anchoring protein is required for protein kinase A regulatory subunit 
localization and morphology of actin structures during oogenesis in Drosophila. Development 129: 4423-4433.

Kelso RJ, Hudson AM, Cooley L. 2002. Drosophila Kelch regulates actin organization via Src64-dependent tyrosine phosphorylation. J Cell Biol 156: 703-713.

Kinoshita M, Field CM, Coughlin ML, Straight AF, Mitchison TJ. 2002. Self- and actin-templated assembly of Mammalian septins. Dev Cell 3: 791-802.

Kramerova IA, Kramerov AA. 1999. Mucinoprotein is a universal constituent of stable intercellular bridges in Drosophila melanogaster germ line and somatic cells. Dev Dyn 216: $349-360$.

Lee HH, Elia N, Ghirlando R, Lippincott-Schwartz J, Hurley JH. 2008. Midbody targeting of the ESCRT machinery by a noncanonical coiled coil in CEP55. Science 322: 576-580.

LeGrand EK. 2001. Genetic conflict and apoptosis. Perspect Biol Med 44: 509-521.

Lin H, Yue L, Spradling AC. 1994. The Drosophila fusome, a germline-specific organelle, contains membrane skeletal proteins and functions in cyst formation. Development 120: 947-956.

Low SH, Li X, Miura M, Kudo N, Quinones B, Weimbs T. 2003. Syntaxin 2 and endobrevin are required for the terminal step of cytokinesis in mammalian cells. Dev Cell 4: 753-759.

Lu N, Guarnieri DJ, Simon MA. 2004. Localization of Tec29 to ring canals is mediated by $\operatorname{Src} 64$ and $\operatorname{PtdIns}(3,4,5) \mathrm{P} 3$ dependent mechanisms. EMBO J 23: 1089-1100.

Martinez-Garay I, Rustom A, Gerdes HH, Kutsche K. 2006. The novel centrosomal associated protein CEP55 is present in the spindle midzone and the midbody. Genomics 87: 243-253.

Matsumura F. 2005. Regulation of myosin II during cytokinesis in higher eukaryotes. Trends Cell Biol 15: 371-377.

Matuliene J, Kuriyama R. 2004. Role of the midbody matrix in cytokinesis: RNAi and genetic rescue analysis of the mammalian motor protein CHO1. Mol Biol Cell 15: 3083-3094.

McGuinness MP, Orth JM. 1992. Reinitiation of gonocyte mitosis and movement of gonocytes to the basement membrane in testes of newborn rats in vivo and in vitro. Anat Rec 233: 527-537.

Miki K, Willis WD, Brown PR, Goulding EH, Fulcher KD, Eddy EM. 2002. Targeted disruption of the Akap4 gene causes defects in sperm flagellum and motility. Dev Biol 248: $331-342$.

Miller KG, Field CM, Alberts BM. 1989. Actin-binding proteins from Drosophila embryos: A complex network of interacting proteins detected by F-actin affinity chromatography. J Cell Biol 109: 2963-2975.

Minestrini G, Mathe E, Glover DM. 2002. Domains of the Pavarotti kinesin-like protein that direct its subcellular distribution: Effects of mislocalisation on the tubulin and actin cytoskeleton during Drosophila oogenesis. J Cell Sci 115: 725-736.

Mische S, Li M, Serr M, Hays TS. 2007. Direct observation of regulated ribonucleoprotein transport across the nurse cell/oocyte boundary. Mol Biol Cell 18: 2254-2263.

Mishima M, Kaitna S, Glotzer M. 2002. Central spindle assembly and cytokinesis require a kinesin-like protein/
RhoGAP complex with microtubule bundling activity. Dev Cell 2: 41-54.

Montaville P, Dai Y, Cheung CY, Giller K, Becker S, Michalak M, Webb SE, Miller AL, Krebs J. 2006. Nuclear translocation of the calcium-binding protein ALG-2 induced by the RNA-binding protein RBM22. Biochim Biophys Acta 1763: 1335-43.

Moens PB, Hugenholtz AD. 1975. The arrangement of germ cells in the rat seminiferous tubule: An electron-microscope study. J Cell Sci 19: 487-507.

Morales CR, Lefrancois S, Chennathukuzhi V, El-Alfy M, Wu X, Yang J, Gerton GL, Hecht NB. 2002. A TB-RBP and Ter ATPase complex accompanies specific mRNAs from nuclei through the nuclear pores and into intercellular bridges in mouse male germ cells. Dev Biol 246: 480-494.

Morita E, Sandrin V, Chung HY, Morham SG, Gygi SP, Rodesch CK, Sundquist WI. 2007. Human ESCRT and ALIX proteins interact with proteins of the midbody and function in cytokinesis. EMBO J 26: 4215-4227.

Nebel BR, Amarose AP, Hacket EM. 1961. Calendar of gametogenic development in the prepuberal male mouse. Science 134: 832-833.

Oakberg EF. 1971. Spermatogonial stem-cell renewal in the mouse. Anat Rec 169: 515-531.

Otegui MS, Verbrugghe KJ, Skop AR. 2005. Midbodies and phragmoplasts: Analogous structures involved in cytokinesis. Trends Cell Biol 15: 404-413.

Pepling ME, Spradling AC. 1998. Female mouse germ cells form synchronously dividing cysts. Development 125: $3323-3328$

Pepling ME, Spradling AC. 2001. Mouse ovarian germ cell cysts undergo programmed breakdown to form primordial follicles. Dev Biol 234: 339-351.

Pepling ME, de Cuevas M, Spradling AC. 1999. Germline cysts: A conserved phase of germ cell development? Trends Cell Biol 9: 257-262.

Postiglione I, Chiaviello A, Palumbo G. 2009. Twilight effects of low doses of ionizing radiation on cellular systems: A bird's eye view on current concepts and research. Med Oncol 27: 495-509.

Rappaport R. 1967. Cell division: Direct measurement of maximum tension exerted by furrow of echinoderm eggs. Science 156: 1241-1243.

Rappaport R. 1986. Establishment of the mechanism of cytokinesis in animal cells. Int Rev Cytol 105: 245-281.

Rasmussen SW. 1973. Ultrastructural studies of spermatogenesis in Drosophila melanogaster Meigen. $Z$ Zellforsch Mikrosk Anat 140: 125-144.

Ren HP, Russell LD. 1991. Clonal development of interconnected germ cells in the rat and its relationship to the segmental and subsegmental organization of spermatogenesis. Am J Anat 192: 121-128.

Rieder CL, Khodjakov A, Paliulis LV, Fortier TM, Cole RW, Sluder G. 1997. Mitosis in vertebrate somatic cells with two spindles: Implications for the metaphase/anaphase transition checkpoint and cleavage. Proc Natl Acad Sci 94: 5107-5112.

Robinson DN, Cooley L. 1996. Stable intercellular bridges in development: The cytoskeleton lining the tunnel. Trends Cell Biol 6: 474-479. 
M.P. Greenbaum et al.

Robinson DN, Cooley L. 1997. Drosophila kelch is an oligomeric ring canal actin organizer. J Cell Biol 138: 799-810.

Robinson DN, Cant K, Cooley L. 1994. Morphogenesis of Drosophila ovarian ring canals. Development 120: 2015-2025.

Roulier EM, Panzer S, Beckendorf SK. 1998. The Tec29 tyrosine kinase is required during Drosophila embryogenesis and interacts with Src64 in ring canal development. $\mathrm{Mol}$ Cell 1: 819-829.

Saez JM, Perrard-Sapori MH, Chatelain PG, Tabone E, Rivarola MA. 1987. Paracrine regulation of testicular function. J Steroid Biochem 27: 317-329.

Satterwhite LL, Pollard TD. 1992. Cytokinesis. Curr Opin Cell Biol 4: 43-52.

Sertoli E. 1877. Sulla struttura dei canalicoli seminiferi dei testicoli studiata in rapport allo sviluppo dei nemaspermi. Arch Sci Med 2: 107-146, 267-295.

Somogyi K, Rorth P. 2004. Cortactin modulates cell migration and ring canal morphogenesis during Drosophila oogenesis. Mech Dev 121: 57-64.

Spradling A, Drummond-Barbosa D, Kai T. 2001. Stem cells find their niche. Nature 414: 98-104.

Stanley HP, Bowman JT, Romrell LJ, Reed SC, Wilkinson RF. 1972. Fine structure of normal spermatid differentiation in Drosophila melanogaster. J Ultrastruct Res 41: 433-466.

Tegelenbosch RA, de Rooij DG. 1993. A quantitative study of spermatogonial multiplication and stem cell renewal in the C3H/101 F1 hybrid mouse. Mutat Res 290: 193-200.

Tilney LG, Tilney MS, Guild GM. 1996. Formation of actin filament bundles in the ring canals of developing Drosophila follicles. J Cell Biol 133: 61-74.

Toure A, Dorseuil O, Morin L, Timmons P, Jegou B, Reibel L, Gacon G. 1998. MgcRacGAP, a new human GTPase-activating protein for Rac and Cdc42 similar to Drosophila rotundRacGAP gene product, is expressed in male germ cells. J Biol Chem 273: 6019-6023.
Van de Putte T, Zwijsen A, Lonnoy O, Rybin V, Cozijnsen M, Francis A, Baekelandt V, Kozak CA, Zerial M, Huylebroeck D. 2001. Mice with a homozygous gene trap vector insertion in mgcRacGAP die during preimplantation development. Mech Dev 102: 33-44.

Ventela S, Toppari J, Parvinen M. 2003. Intercellular organelle traffic through cytoplasmic bridges in early spermatids of the rat: Mechanisms of haploid gene product sharing. Mol Biol Cell 14: 2768-2780.

von Dassow G, Bement WM. 2005. A ring-like template for abscission. Dev Cell 9: 578-580.

von Ebner V. 1888. Zur Spermatogenese bei den Saugethieren. Arch Mikrosk Anat 31: 236-292.

Wang YL. 2005. The mechanism of cortical ingression during early cytokinesis: thinking beyond the contractile ring hypothesis. Trends Cell Biol 15: 581-588.

Wang PJ, McCarrey JR, Yang F, Page DC. 2001. An abundance of X-linked genes expressed in spermatogonia. Nat Genet 27: 422-426.

Weber JE, Russell LD. 1987. A study of intercellular bridges during spermatogenesis in the rat. Am J Anat 180: 1-24.

Witkin JW, O’Sullivan H, Silverman AJ. 1995. Novel associations among gonadotropin-releasing hormone neurons. Endocrinology 136: 4323-4330.

Wu MH, Rajkovic A, Burns KH, Yan W, Lin YN, Matzuk MM. 2003. Sequence and expression of testis-expressed gene 14 (Tex14): A gene encoding a protein kinase preferentially expressed during spermatogenesis. Gene Expr Patterns 3: 231-236.

Yue L, Spradling AC. 1992. hu-li tai shao, a gene required for ring canal formation during Drosophila oogenesis, encodes a homolog of adducin. Genes Dev 6: 2443-2454.

Zhao WM, Seki A, Fang G. 2006. Cep55, a microtubulebundling protein, associates with centralspindlin to control the midbody integrity and cell abscission during cytokinesis. Mol Biol Cell 17: 3881-3896. 


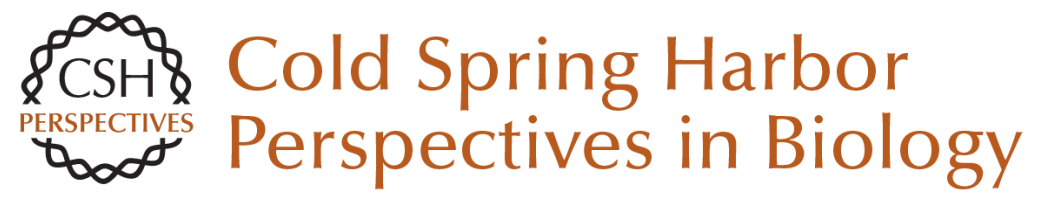

\section{Germ Cell Intercellular Bridges}

Michael P. Greenbaum, Tokuko Iwamori, Gregory M. Buchold and Martin M. Matzuk

Cold Spring Harb Perspect Biol 2011; doi: 10.1101/cshperspect.a005850 originally published online June 13,2011

\section{Subject Collection Germ Cells}

RNA Granules in Germ Cells

Ekaterina Voronina, Geraldine Seydoux, Paolo

Sassone-Corsi, et al.

Function of the Sex Chromosomes in Mammalian

Fertility

Edith Heard and James Turner

Small Noncoding RNAs in the Germline

Jonathan P. Saxe and Haifan Lin

Mammalian Genomic Imprinting

Marisa S. Bartolomei and Anne C. Ferguson-Smith

Molecular Regulation of the Mitosis/Meiosis

Decision in Multicellular Organisms Judith Kimble

Selection in the Rapid Evolution of Gamete Recognition Proteins in Marine Invertebrates Victor D. Vacquier and Willie J. Swanson
Developmental Control of Oocyte Maturation and

Egg Activation in Metazoan Models Jessica R. Von Stetina and Terry L. Orr-Weaver

Translational Control in Oocyte Development Joel D. Richter and Paul Lasko

Unique Aspects of Transcription Regulation in Male Germ Cells

Helen White-Cooper and Irwin Davidson

Germ Cell Intercellular Bridges

Michael P. Greenbaum, Tokuko Iwamori, Gregory M. Buchold, et al.

Germline Stem Cells

Allan Spradling, Margaret T. Fuller, Robert E. Braun, et al.

Nuclear Transfer to Eggs and Oocytes J. B. Gurdon and lan Wilmut

For additional articles in this collection, see http://cshperspectives.cshlp.org/cgi/collection/

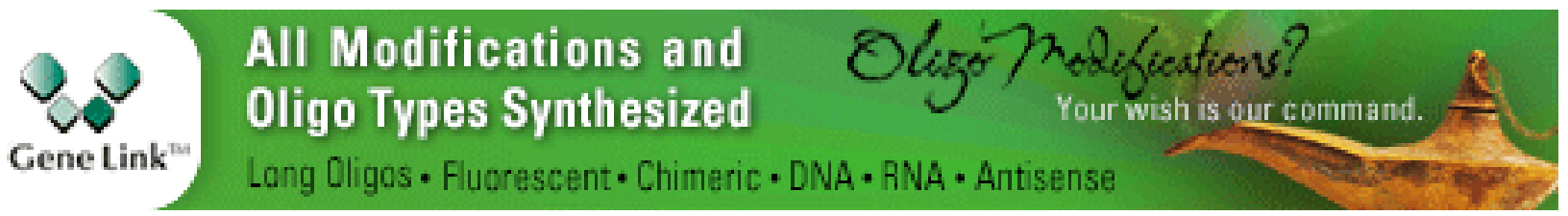

Copyright @ 2011 Cold Spring Harbor Laboratory Press; all rights reserved 